\title{
Identyfikacja domieszek V, Co, Ni i Au w mineralach kruszcowych rud Fe-Ti-V (NE Polska) na podstawie analiz mikrosondą rentgenowską (EMPA)
}

\author{
Sadłowska Katarzyna ${ }^{1}$, Stanisław Z. Mikulski ${ }^{1}$
}

Electron microprobe study of V, Co, Ni and Au admixtures in ore minerals from Fe-Ti-V deposits (NE Poland). Prz. Geol., 67: 192-195; doi: 10.7306/2019.18

A b s tr a c t. The main objective of this study was to quantitatively and qualitatively idenify trace metal admixtures in ore minerals from Fe-Ti-Vore deposits within the Suwatki Anorthosite Massif in NE Poland. Chemical composition of ore minerals was determined using the CAMECA SX-100 electron microprobe and scanning electron microscope. The most abundant trace elements were Ti and Vhosted in oxides and $\mathrm{Co}, \mathrm{Ni}, \mathrm{Cu}, \mathrm{Zn}$ contained in sulphides such as pentlandite, pyrrhotite, chalcopyrite, pyrite, siegenite, millerite. Scarce occurrences of native Bi, hessite and greenockite were identified. Samples, which were depleted in iron oxides were enriched in REE due to the presence of zircon, apatite and monazite.

Keywords: vanadium, cobalt, gold, trace elements, Fe-Ti-V deposits, NE Poland

W ramach realizacji zadań państwowej służby geologicznej w latach 2015-2018 prowadzono projekt badawczy, którego celem była analiza ilościowo-jakościowa pierwiastków towarzyszących, w tym krytycznych, występujących w rudach metali udokumentowanych złóż reprezentujących główne formacje metalogeniczne w Polsce oraz identyfikacja ich głównych nośników (Mikulski i in., 2018b). Przedmiotem badań były między innymi rdzenie skał pochodzące $\mathrm{z}$ archiwalnych wierceń dokumentujących mezoproterozoiczne rudy magmowe Fe-Ti-V w suwalskim masywie anortozytowym w NE Polsce.

W artykule przedstawiono wyniki komplementarnych badań mineralogiczno-petrograficznych nośników pierwiastków śladowych w bilansowych rudach magnetytowo-ilmenitowych $\mathrm{z}$ wanadem w norytach i anortozytach z obszaru złóż Krzemianka i Udryń w masywie suwalskim za pomocą optycznego mikroskopu polaryzacyjnego oraz mikrosonda elektronową CAMECA SX-100 (Subieta, 1971; Kubicki, Siemiątkowski, 1979; Cieśla, Wybraniec, 1998; Juskowiak, 1998; Parecki, 1998; Ryka, 1998; Ryka, Szczepanowski, 1998; Wiszniewska, 2002; Wiszniewska i in., 2018).

\section{WYNIKI}

Rudy Fe-Ti-V występują w skale w postaci soczew ferrolitów, minerały kruszcowe mogą być też rozproszone $\mathrm{w}$ anortozytach i norytach, spotyka się również żyły nelsonitowe (Wiszniewska, 2002, wraz z literatura). Wszystkie zbadane próbki skał magnetytowo-ilmenitowych, czyli ferrolitów, pochodzą z interwałów bilansowych rudy. Są to skały ciemnoszare lub czarne, ciężkie. Na polerowanych powierzchniach tych skał widać metaliczny połysk. Przeprowadzone badania potwierdziły wyniki wcześniej publikowanych prac (Kubicki, Siemiątkowski, 1979; Kozłowska, Wiszniewska, 1991; Speczik, 1991; Wiszniewska, 2002; Marcinkowski, 2006), że głównymi minerałami kruszcowymi są magnetyt i ilmenit, które w ferrolitach stanowią ponad $90 \%$ objętości skały (ryc. 1A, B, F). W rudach tych podrzędnie występują siarczki, reprezentowane przede wszystkim przez pirotyn, chalkopiryt i pentlandyt (ryc. 1D, F), które mogą stanowić do 3-4\% rudy. Ponadto w badanych próbkach rud zidentyfikowano pleonast, piryt, bravoit, vio-

\section{$\longrightarrow$}

Ryc. 1. Typowa ruda magnetytowo-ilmenitowa z siarczkami ze złóż Krzemianka i Udryń w suwalskim masywie anortozytowym (NE Polska): A - Typowe wykształcenie magnetytu w postaci masywnych kryształów z wrostkami spinelu i przerostami ilmenitu w formie lamelek z odmieszania (światło odbite, $1 \mathrm{~N}$ ); B - Strefa frontu ilmenityzacji magnetytu, relikty magnetytu w obrębie ilmenitu podkreślają zarys pierwotnych ziaren (światło odbite, $1 \mathrm{~N}$ ); $\mathbf{C}$ - Wrostki bizmutu rodzimego w magnetycie, przerosty magnetytu z apatytem (obraz BSE, $15 \mathrm{kv}$ ); D - Typowy agregat siarczkowy. Pierwotny pirotyn, pentlandyt i chalkopiryt zostały objęte procesami wtórnej mineralizacji (obraz BSE, $15 \mathrm{kV}$ ); $\mathbf{E}$-Ziarno hemo-ilmenitu, ciemniejsze szare tło stanowi ilmenit, jaśniejsze lamelki hematyt (światło odbite, $1 \mathrm{~N}$ ); $\mathbf{F}$ - Typowy agregat siarczków magmowych zbudowany z pirotynu, pentlandytu i chalkopirytu (światło odbite, $1 \mathrm{~N}$ ); G - Ziarno pirotynu objęte pirytyzacją (światło odbite, $1 \mathrm{~N}$ ); H - Milleryt zastępuje chalkopiryt (obraz BSE, $15 \mathrm{kv}$ ). Bi - bizmut rodzimy, Co-py - piryt kobaltonośny, cp - chalkopiryt, ilm - ilmenit, mgt - magnetyt, mlr - milleryt, pn - pentlandyt, Po - pirotyn, py piryt, sie - sigenit, Spl - spinel

Fig. 1. Typical magnetite-ilmenite ore with sulphides from the Krzemianka and Udryń Fe-Ti-V ore deposits in the Suwałki Anorthosite Massif(NE Poland): A-Massive magnetite grain with ilmenite exsolution lamellae and rounded spinel inclusions. Reflected light, 1N; B - Ilmenitization zone, relics of magnetite in place of primary grain shape. Reflected light, $1 \mathrm{~N} ; \mathbf{C}$ - Inclusions of native bismuth in magnetite, apatite grain intergrown with magnetite. BSE image, $15 \mathrm{kV} ; \mathbf{D}$ - Typical sulphide aggregate. Primary pyrrhotite, pentlandite and chalcopyrite showing secondary alteration. BSE image, $15 \mathrm{kV} ; \mathbf{E}-$ Hemo-ilmenite grain, ilmenite in dark grain background, light grey lamellae are hematite. Reflected light, $1 \mathrm{~N} ; \mathbf{F}$ - Typical sulphide aggregate formed of pyrrhotite, pentlandite and chalcopyrite. Reflected light, 1N; G - Pyritized pyrrhotite grain. Reflected light, 1N; H - Chalcopyrite partly replaced with millerite. BSE image, $15 \mathrm{kV}$. Bi - native bismuth, Co-py - cobalt-bearing pyrite, $\mathbf{c p}$ - chalcopiryte, ilm - ilmenite, mgt - magnetite, $\mathbf{m l r}$ - millerite, pn pentlandite, $\mathbf{P o}$ - pyrrhotite, py - pyrite, sie - siegenite, Spl - spinel

${ }^{1}$ Państwowy Instytut Geologiczny - Państwowy Instytut Badawczy, ul. Rakowiecka 4; 00-975 Warszawa 


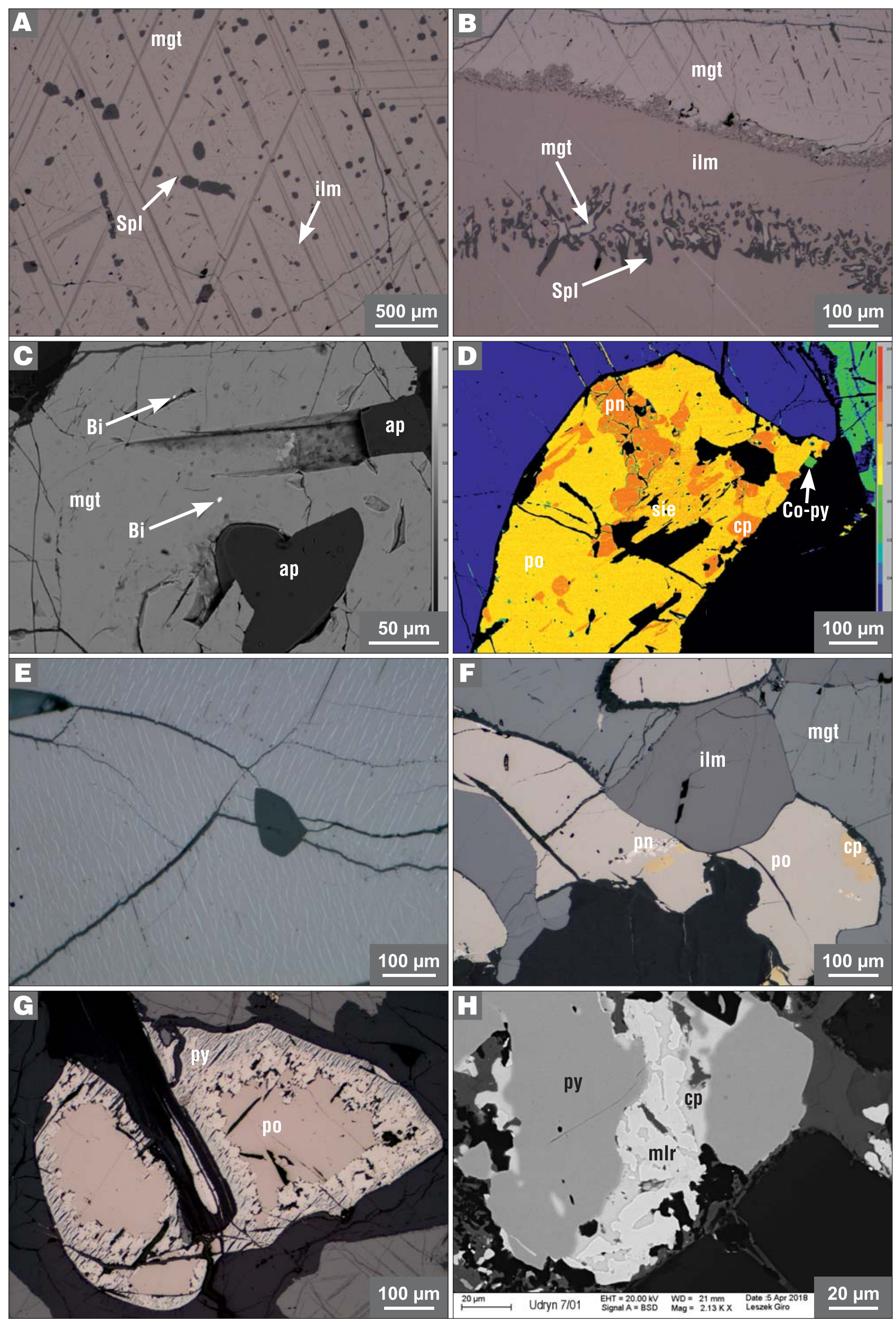


laryt, sigenit, kubanit, galenę, wrostki bizmutu rodzimego, greenockitu i hessytu.

Najważniejszą domieszką w bilansowych rudach żelaza masywu suwalskiego jest wanad, którego udokumentowane zasoby pozabilansowe wynoszą $4,1 \mathrm{mln} \mathrm{t}$ (Szuflicki $\mathrm{i}$ in., 2018). Jednak brzeżna wartość ekwiwalentna $\mathrm{V}_{2} \mathrm{O}_{5} \mathrm{~W}$ rudzie bilansowej powinna wynosić $0,73 \%$. Po przyjęciu takiego kryterium zasoby suwalskich rud wynosiłyby zaledwie 1\% wcześniej udokumentowanych zasobów (Nieć, 2003). Na podstawie badań mikrosondą elektronową stwierdzono, że magnetyt zawiera średnio ok. $0,42 \%$ wag. $\mathrm{V}$ i jest głównym nośnikiem tego metalu. Zawartość wanadu w magnetycie zmienia się w granicach od 0,006 do $0,59 \%$ wag. Wanad stanowi domieszkę izomorficzną w magnetycie, podstawiając $\mathrm{Fe}^{3+}$ w jego sieci krystalicznej (Speczik, 1991).

Istotną domieszką jest również Ti, który w magnetycie występuje w trzech formach: 1) tworzy podstawienia izomorficzne w sieci krystalicznej, 2) wchodzi w skład lamelek ilmenitu oraz 3) wchodzi w skład przerostów ulvitu (Kubicki, Siemiątkowski, 1979; Kozłowska, Wiszniewska, 1991). Głównym nośnikiem tytanu jest ilmenit, który w badanych skałach występuje w postaci jednorodnych kryształów, odmieszań w magnetycie oraz w postaci kryształów mieszanych hemo-ilmenitu.

Ilmenit, podobnie jak magnetyt, może zawierać V, jednak w mniejszych ilościach, tj. do $0,27 \%$ wag. (średnio 0,14\% wag.). Zawartość wanadu w hemo-ilmenitach skał płonnych jest kilka lub kilkanaście razy większa niż w ilmenitach jednorodnych z rud (Kubicki, Siemiątkowski, 1979; Kozłowska, Wiszniewska, 1991). Zawartość Ti w magnetycie zmienia się w granicach od 0,019 do 3,51\% wag. (średnio 0,66\% wag.). Ponadto w ilmenicie może się pojawiać $\mathrm{Al}$ - do 4,42\% wag., $\mathrm{Mg}$ - do 1,68\% wag i $\mathrm{Mn}$ - do $1,18 \%$ wag. Spinele szeregu pleonast-hercynit są nośnikami Fe, Al, Mg, Zn, Cr i Ti.

Najczęściej spotykanym siarczkiem jest pirotyn, współwystępujący z chalkopirytem i pentlandytem (ryc. 1D, F), niekiedy także z siegenitem. Agregaty te często tworzą przerosty z magnetytem i ilmenitem. Pirotyn jest często zastępowany przez wtórny piryt, chalkopiryt zaś przez milleryt (ryc. $1 \mathrm{G}, \mathrm{H}$ ). W pirotynie stwierdzono niewielkie domieszki złota (ryc. 2). Jednak koncentracje złota w ferrolitach są bardzo niskie (średnia geometryczna $=3,5 \mathrm{ppb}$, Mikulski i in., 2018a). Złoto wykazuje silną korelację z Cu $(\mathrm{r}=0,85)$ i Ni $(\mathrm{r}=0,62)$, co sugeruje współwystępowanie $\mathrm{z}$ chalkopirytem lub pentlandytem.

Piryt w badanych skałach rzadko występuje w postaci automorficznej. W agregatach objętych procesami wtórnymi często pojawia się wtórny siarczek krystalizujący wzdłuż spękań pierwotnych minerałów o składzie chemicznym średnio $39-42 \%$ wag. S, 26,93\% wag. $\mathrm{Ni}$, 18,31\% wag. Co oraz 13,79\% wag. Fe. Zawartość siarki jest odpowiednia dla siegienitu lub smythytu, który powstaje jako produkt niskotemperaturowych przemian silnie magnetycznego, jednoskośnego pirotynu. Jednak proporcje metali wskazują na występowanie podstawień diadochowych bądź mikrozrosty kilku faz. Pentlandyt cechują znaczne domieszki Co, nawet do 15,3\% wag., natomiast pirotyn zawiera domieszki Ni do $4 \%$ wag. (ryc. 3).

Dodatkowo na podstawie badań mikrosondą elektronową oraz pod mikroskopem skaningowym zidentyfikowano pojedyncze wystąpienia następujących minerałów: $\square$ greenockit w postaci wrostków i żyłek w chalkopirycie;

$\square$ wrostki bizmutu rodzimego w magnetycie i pirotynie (ryc. 1C);

$\square$ ziarna hessytu o rozmiarach 1-2 $\mu \mathrm{m}$ na brzegach ziaren chalkopirytu;

$\square$ sfaleryt o rozmiarach od 1 do kilku $\mu \mathrm{m}$ w postaci wrostków w chalkopirycie, a także występujący obok chlorytu jako wypełnienie spękań w piroksenach i spinelach. Nieregularne, amebowate ziarna sfalerytu, o wielkości $50 \mu \mathrm{m}$, są spotykane w sąsiedztwie chlorytów tworzących masywne skupienia;

$\square$ galenę, o rozmiarach 2-3 $\mu \mathrm{m}$, w pseudomorfozach pirytu po pirotynie, krzemianach skałotwórczych, ilmenitowych listewkach z odmieszania oraz w siegenicie.

Ponadto w próbkach o mniejszej zawartości minerałów nieprzezroczystych, sięgającej ok. 40\%, stwierdzono występowanie nośników ziem rzadkich, takich jak apatyt, monacyt i cyrkon (ryc. 1C).

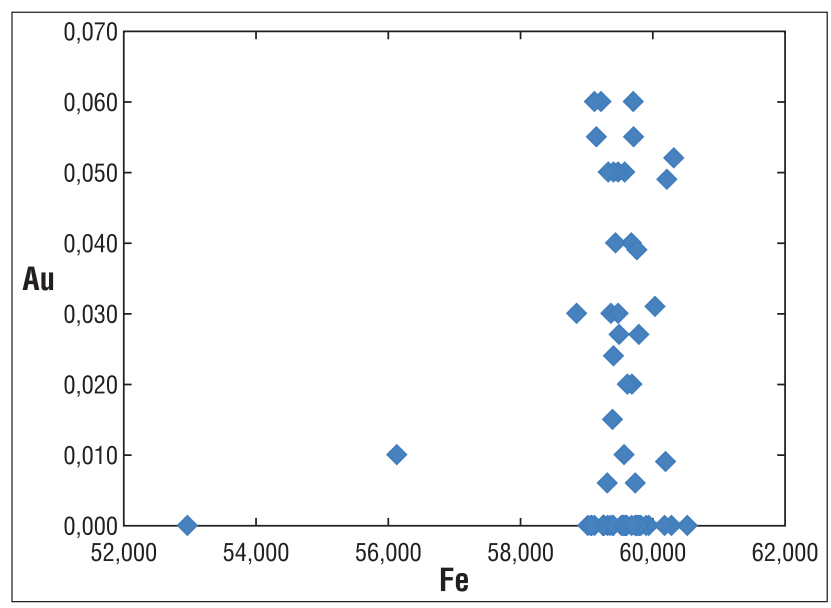

Fig. 2. Wykres rozrzutu zawartości złota (w \% wag.) w stosunku do zawartości żelaza w pirotynie (w \% wag.) na podstawie badań mikrosonda elektronowa CAMECA SX-100

Fig. 2. Admixture variability of gold (in wt\%) vs. iron within pyrrhotite (in wt $\%$ ) based on EMPA

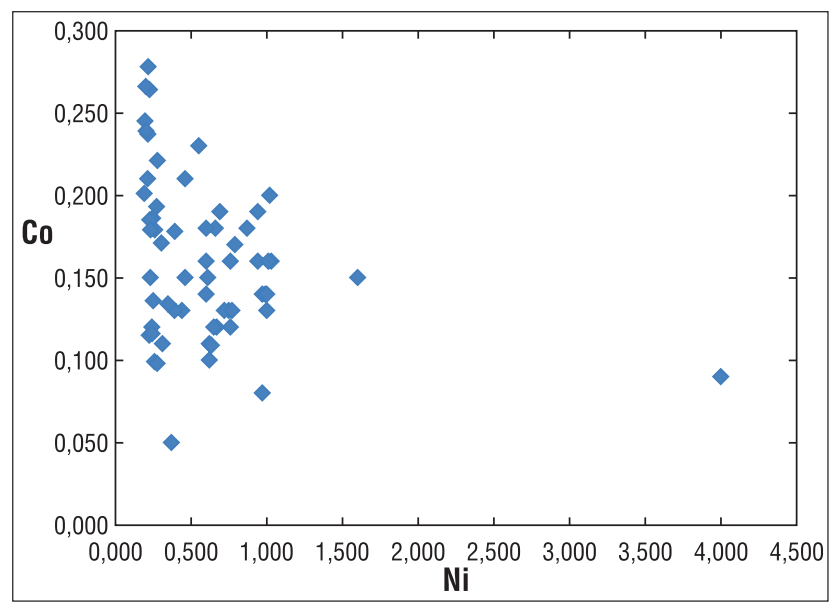

Fig. 3. Wykres rozrzutu zawartości niklu (w \% wag.) w stosunku do zawartości kobaltu (w \% wag.) w pirotynie na podstawie badań mikrosondą elektronową CAMECA SX-100

Fig. 3. Admixture variability of nickel (in wt $\%$ ) vs. cobalt (in wt $\%$ ) within pyrrhotite based on EMPA 


\section{WNIOSKI}

Na podstawie szczegółowych badań mikroskopowych i analiz składu chemicznego w mikroobszarze zidentyfikowano nośniki pierwiastków śladowych istotnych z ekonomicznego punktu widzenia oraz stwierdzono obecność minerałów dotychczas słabo lub w ogóle nieznanych w złożach rud Fe-Ti-V Krzemianka i Udryń. Zidentyfikowano $\mathrm{m}$.in. wrostki $\mathrm{Bi}$ rodzimego $\mathrm{w}$ magnetycie i pirotynie oraz hessytu $\left(\mathrm{Ag}_{2} \mathrm{Te}\right)$ i greenockitu $(\mathrm{CdS}) \mathrm{w}$ chalkopirycie, a także nośniki pierwiastków krytycznych (pentlandyt, pirotyn, chalkopiryt, piryt, magnetyt) i rzadkich (cyrkon, monacyt, apatyt).

Badania prowadzono w ramach realizacji zadań państwowej służby geologicznej ze środków NFOŚiGW.

\section{LITERATURA}

CIEŚLA E., WYBRANIEC S. - 1998. Geophysical studies of the Suwałki Anorthosite Massif. Pr. Państw. Inst. Geol., 161: 39-46.

JUSKOWIAK O. 1998 - Occurence, structure and mineral diversity of rocks from the Suwałki Anorthosite Massif. Pr. Państw. Inst. Geol., 161: 53-80.

KOZŁOWSKA A., WISZNIEWSKA J. 1991 - Aspekty genetyczne tekstur i struktur minerałów kruszcowych w masywie suwalskim. Arch. Mineral., 44, 2: 69-88.

KUBICKI S., SIEMIATKOWSKI J. 1979 - Mineralizacja kruszcowa suwalskiego masywu zasadowego. Biul. Inst. Geol., 316 (3): 5-136. MARCINKOWSKI B. 2006 - Prawidłowości występowania mineralizacji kruszcowej w wybranych kompleksach fundamentu krystalicznego północno-wschodniej Polski. Biul. Państw. Inst. Geol., 421: 53-90.
MIKULSKI S.Z., OSZCZEPALSKI S., SADŁOWSKA K., CHMIELEWSKI A., MAŁEK R. 2018a - Wystepowanie pierwiastków towarzyszących i krytycznych w wybranych udokumentowanych złożach rud $\mathrm{Zn}-\mathrm{Pb}, \mathrm{Cu}-\mathrm{Ag}$, Fe-Ti-V, Mo-Cu-W, Sn, Au-As i Ni w Polsce, Biul. Państw. Inst. Geol., 472: 21-52.

MIKULSKI S.Z., SADŁOWSKA K., OSZCZEPALSKI S., CHMIELEWSKI A., MAŁEK R., 2018b - Weryfikacja formacji metalogenicznych w Polsce w aspekcie występowania surowców rzadkich i krytycznych. Nar. Arch. Geol. nr 5685/2018, Państw. Inst. Geol.-PIB, Warszawa.

NIEĆ M. 2003 - Ocena geologiczno-gospodarcza złóż wanadonośnych rud tytanomagnetytowych masywu suwalskiego. Gosp. Sur. Miner., 19 (2): 5-27.

PARECKI A. 1998 - Geological structure of Krzemianka and Udryn deposits. Pr. Państw. Inst. Geol., 161: 123-136.

RYKA W. 1998 - Geological positions of the Suwałki Anorthosite Massif. Pr. Państw. Inst. Geol., 161: 19-26.

RYKA W., SZCZEPANOWSKI H. 1998 - Trace elements of the Suwałki Anorthosite Massif. Pr. Państw. Inst. Geol., 161: 105-110.

SPECZIK S. 1991 - Distribution of vanadium in ore minerals of the Suwałki massif (Northeastern Poland). Arch. Mineral., 44 (2): 19-36. SUBIETA M. 1971 - Dokumentacja geologiczna złoża rud żelaza, tytanu i wanadu Krzemianka, powiat suwalski, woj. Białystok. Nar. Arch. Geol. Państw. Inst. Geol.-PIB, Warszawa.

SZUFLICKI M., MALON A., TYMIŃSKI M. (red.) 2018 - Bilans zasobów złóż kopalin w Polsce wg stanu na 31.12.2017. Państw. Inst. Geol.PIB, Warszawa.

WISZNIEWSKA J. 2002 - Wiek i geneza rud Fe-Ti-V i skał towarzyszących w suwalskim masywie anortozytowym (NE Polska). Biul. Państw. Inst. Geol., 401: 1-96.

WISZNIEWSKA J., KRZEMIŃSKA E., POLECHOŃSKA O., PETECKI Z., RUSZKOWSKI M., SALWA S. 2018 - Nowe rezultaty badań mineralizacji polimetalicznej, PGE i REE w Suwalskim Masywie Anortozytowym (NE Polska). Biul. Państw. Inst. Geol., 472: 271-284. 